\title{
Educação e Tecnologia: Inclusão Digital na Microrregião de Itaparica-PE
}

\author{
Ítalo H. S. Silva ${ }^{1,2}$, Yuri L. S. F. Magalhães ${ }^{1,2}$, Cassiano H. de Albuquerque ${ }^{1,2}$ \\ ${ }^{1}$ Instituto Federal de Educação, Ciência e Tecnologia do Sertão Pernambucano - \\ Campus Floresta - PE - Brazil \\ ${ }^{2}$ GITEG - Grupo de Pesquisa em Inovações Tecnológicas na Gestão de Hardware, \\ Software e Peopleware. \\ \{herbertitalo, yuhferraz\}@hotmail.com, cassiano.henrique@ifsertao- \\ pe.edu.br
}

\begin{abstract}
This work includes the results of two years of research with the students included in the program "Aluno Conectado" the government state Pernambuco. This program has distributed computers to the students of the second and third years of high school enrolled in state schools. The reality of these students and presented the results of a training project was analyzed to assist digital inclusion thereof. Note before the results were that the needs of students are similar to the level of knowledge technological.
\end{abstract}

Resumo. Este trabalho contempla os resultados de dois anos de pesquisas realizadas com os discentes contemplados no programa Aluno Conectado do governo do estado de Pernambuco. Este programa distribuiu computadores para os discentes dos segundos e terceiros anos do ensino médio matriculados na rede estadual de ensino. Foi analisada a realidade desses alunos e é apresentado os resultados de um projeto de capacitação para auxiliar a inclusão digital dos mesmos. Diante dos resultados nota-se que as necessidades dos alunos são semelhantes em relação ao nível de conhecimento tecnológico.

\section{Introdução}

O Programa Aluno Conectado surgiu com uma iniciativa inovadora do governo do estado de Pernambuco, onde em 2012, foram distribuídos os PCs conversíveis em tablets para todos os alunos da rede estadual matriculados no $2^{\circ}$ e no $3^{\circ}$ ano do ensino médio, tendo como objetivo a promoção da inclusão digital no ambiente escolar (Educar, 2014). Este programa entregou em torno de 370 mil tablets entre os anos de 2012 a 2014 (Secretaria de Educação e Esportes de Pernambuco, 2014). Este programa possui como objetivo principal a promoção da inclusão digital entre os discentes do ensino médio. Também como objetivos secundários o programa intencionava a melhoria do rendimento escolar dos alunos. "[...] As novas abordagens podem motivá-los, e podem ganhar e segurar sua atenção para a ciência, matemática, ou tecnologia por atrair sua personalidade em tarefas que significam algo para eles." (Black e Myron, 2005). Ferreira e Wagner (2012) afirmam que com a velocidade e disponibilidade altíssima das informações, o surgimento de novas tecnologias ou mesmo de novas formas de interação com elas é quase que diário. Os alunos da escola de hoje, nascidos na era 
digital, tem domínio sobre estas tecnologias e acompanham seu avanço. Analisando os dados da pesquisa CETIC.BR (2013) nota-se que em 2010, a área urbana do Brasil contava com $39 \%$ de domicílios com computador, enquanto essa proporção na área rural era de $12 \%$. E em 2013, 53\% na zona urbana e $21 \%$ na zona rural. Através desses dados é possível observar um crescimento maior na utilização de computadores na zona urbana do que na zona rural.

A hipótese analisada nesta pesquisa consiste em avaliar o nível de conhecimento tecnológico dos discentes contemplados e avaliar a necessidade de capacitação complementar para garantir a real inclusão digital por parte do público contemplado. "Essas transformações, claramente, afetarão os nossos sistemas de educação e demandarão às escolas novos espaços e cenários de aprendizagem. Todavia, antes de imaginar qualquer mudança, precisaremos de uma reforma de pensamento" (Scaico e Queiroz, 2013).

\section{Metodologia}

Através do programa Aluno Conectado foram realizadas aulas expositivas, palestras e oficinas, onde os alunos aprenderam mais sobre internet, componentes físicos e lógicos do computador, também foi feita uma análise de conhecimento, através de questionários avaliativos para poder medir o nível de conhecimento que os alunos estavam antes, e depois da capacitação que foi ministrada. Para facilitar o processo de análise dos dados obtidos e garantir a confiabilidade do estudo, construiu-se, ao longo da pesquisa uma base de dados cujos registros foram feitos através da tabulação das respostas dos questionários aplicados.

A Tabela 1, possui as análises sobre os alunos, municípios, quantidade de escolas e turmas beneficiados pelo programa.

Tabela 1. Relação entre Município, Escola, Alunos e Turmas.

\begin{tabular}{|c|c|c|c|}
\hline Município & Quantidade de escolas & Quantidade de alunos & Turmas \\
\hline Floresta-PE & 6 & 107 & 6 \\
\hline Belém do São Francisco-PE & 5 & 443 & 14 \\
\hline Carnaubeira da Penha-PE & 2 & 141 & 5 \\
\hline Petrolândia-PE & 5 & 422 & 19 \\
\hline Tacaratu-PE & 2 & 134 & 5 \\
\hline Itacuruba-PE & 1 & 111 & 3 \\
\hline Total & 21 & 1358 & 52 \\
\hline
\end{tabular}

Foi feito um cálculo para descobrir o tamanho mínimo da amostra conforme o número de alunos da tabela 1 , o número de alunos foi superior ao tamanho mínimo da amostra e o grau de confiança utilizado foi o de 95\%, com uma margem de erro de $2,5 \%$. O cálculo é mostrado a seguir:

$$
\frac{N=(Z a / 2)^{2} \bar{p} \bar{q}}{E^{2}}
$$


CBIE-LACLO 2015

Anais do XXI Workshop de Informática na Escola (WIE 2015)

$$
\begin{gathered}
\frac{N=3,8416 \times 0,25 \times(1-0,25)}{0,025^{2}} \\
\frac{N=3,8416 \times 0,25 \times 0,75}{0,000625} \\
\frac{N=0,7203}{0,000625}=1152,48
\end{gathered}
$$

Conforme explicitado na Tabela 1, o número da amostra de 1358 discentes foi superior ao tamanho mínimo estatisticamente calculado de 1153 discentes, o que valida o experimento.

\section{Resultados Obtidos}

A forma utilizada para avaliar os alunos, consistiu em realizar uma palestra para os alunos sobre o Tablet-PC e sobre informática básica, os discentes participam das aulas, interagindo durante as palestras, dando opiniões e fazendo pergunta sobre os assuntos abordados. Depois da palestra os alunos responderam um questionário com alternativas sobre conhecimentos básicos de informática e sobre seus Tablets, onde alguns alunos responderam o questionário antes da capacitação, e depois da capacitação, esse processo foi realizado com os alunos da zona urbana e com os alunos da zona rural.

No questionário tinham perguntas como: O que é software? O que é Hardware? Qual a função básica de um processador? Quando o meu computador estiver com o antivírus desatualizado o que devo fazer? O que é uma memória RAM? O que é um Hard Disk? O que é um pen drive? O Tablet disponibiliza para a utilização acadêmica alguns softwares, qual software pode ser utilizado para facilitar o aprendizado em sala de aula? Essas foram algumas das perguntas que foram feitas para poder medir o nível de conhecimento dos alunos sobre o seu Tablet-PC e sobre informática básica.

O objetivo é realizar comparações entre a diferença nas médias dos questionários aplicados na zona urbana e na zona rural, para analisar se houve diferença significativa ou não.

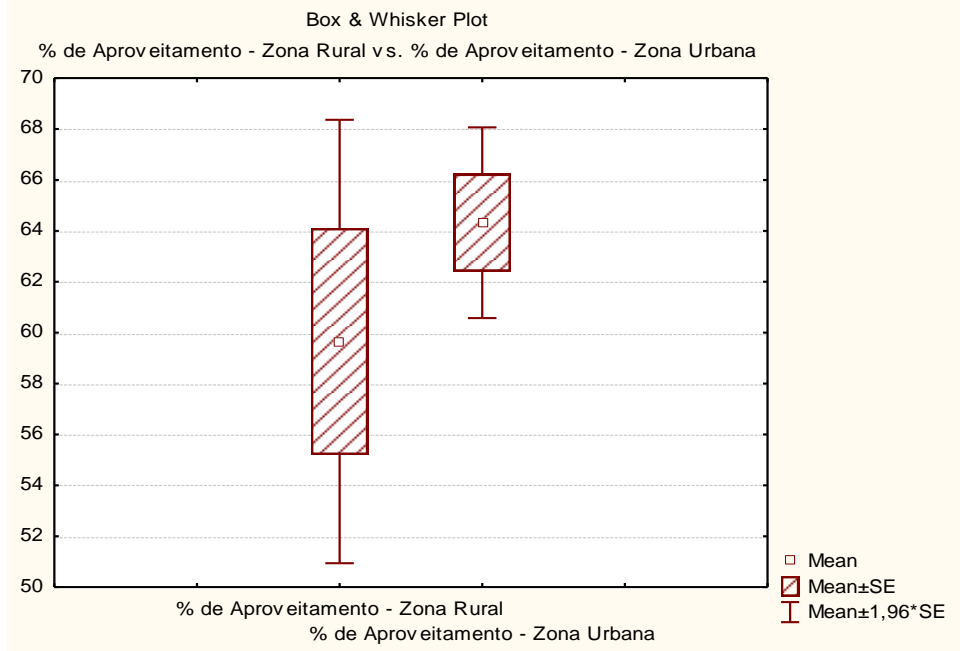

Figura 1. Gráfico com a média geral de aproveitamento das escolas por zonas. 
Através do gráfico de bloxpot da Figura 1, é exibida a porcentagem de aproveitamento nas escolas da zona rural e nas escolas da zona urbana, e percebe-se que as escolas da área rural tiveram um desempenho um pouco menor do que as escolas da zona urbana.

Tabela 2. Teste T.

\begin{tabular}{|c|c|c|c|c|c|c|}
\hline \multicolumn{7}{|c|}{ Teste t para amostras independentes } \\
\hline & Média - Grupo 1 & Média - Grupo 2 & Valor T & Df & P & $\begin{array}{c}\text { t } \\
\text { separ. } \\
- \\
\text { var.est. }\end{array}$ \\
\hline $\begin{array}{c}\% \text { de } \\
\text { Aproveitamento - } \\
\begin{array}{c}\text { Zona Rural vs. \% } \\
\text { de } \\
\text { Aproveitamento - } \\
\text { Zona Urbana }\end{array}\end{array}$ & 59,6514 & 64,32 & $-1,0874$ & 30 & 0,2855 & $-0,9649$ \\
\hline
\end{tabular}

$\mathrm{Na}$ Tabela 2, foi realizado o Teste T estatístico, com a finalidade de identificar se houve uma diferença significativa ou não nas médias, a média de aproveitamento na zona rural foi de $59,6 \%$, e na zona urbana foi de $64,3 \%$, podemos observar que não houve uma diferença significativa e que de acordo com o valor de $\mathrm{p}$, que foi 0,282505 a hipótese nula foi rejeitada.

\section{Considerações Finais}

Analisando todos os dados levantados durante dois anos de experiências vividas entre 2013 e 2014 vivenciados nas 21 escolas existentes da região, consolidados através dos números e estatísticas obtidos, observou-se que os alunos das escolas da zona urbana se saíram um pouco melhor do que os alunos da zona rural no que diz respeito ao conhecimento em tecnologia e informática básica. Os discentes da zona rural tiveram um pouco mais de dificuldade pois em geral o acesso tecnologia nessas áreas é limitada em comparação com a da zona urbana, onde por exemplo alguns estudantes nunca tiveram a oportunidade de ter acesso a um computador antes de receberem os TabletsPC. Mas, apesar desta diferença os resultados obtidos na pesquisa não apresentaram uma diferença estatisticamente significativa entre o nível de conhecimento prévio em tecnologia.

Entrevistando os alunos nas próprias instituições de ensino verificamos que os muitos problemas relatados no uso da ferramenta entregue tinham uma causa comum. Esses problemas surgiram por falta de uma capacitação ou treinamento adequado para receberem o equipamento tecnológico, os alunos receberam, mas não tiveram instruções, ou qualquer outro tipo de informação, por esse motivo ficaram desnorteados, pelo pouco conhecimento sobre o assunto, e acabaram fazendo escolhas que não eram cabíveis diante daquela situação.

Diante dessas problemáticas faltou junto com a iniciativa o governo ter oferecido capacitações periódicas para que os alunos conseguissem utilizar os seus Tablets-PCs sem maiores problemas. Mas a falta de conhecimento básico sobre informática básica limitou os recursos dos estudantes, eles acabaram tendo mais dificuldades e a inclusão 
digital não alcançada plenamente. Observou-se que os problemas com as máquinas entregues tornam-se até um motivo para que o professor não utilize a ferramenta em sala de aula, ou utilize muito pouco o que deveria facilitar a vida dos alunos e consequentemente dos professores.

É proposto assim, através desta pesquisa, que o fornecimento da tecnologia seja complementado com uma capacitação periódica fornecida pelo poder público a fim de maximizar a inclusão digital dos estudantes e fomentar a melhoria da educação em geral.

\section{Referências}

CETIC.BR. Pesquisa sobre o uso das tecnologias da informação e comunicação nas escolas brasileiras. Nov.2014. Disponível em: $<$ http://cetic.br/publicacao/pesquisasobre-o-uso-das-tecnologias-de-informacao-e-comunicacao-nas-escolas-brasileirastic-educacao-2013/>

Educar. Intel ${ }^{\circledR} \quad$ Education no $\quad$ Brasil. $\quad$ Disponível $\mathrm{em}:<\mathrm{http}: / /$ www.educar.editorasegmento.com.br/anunciante/36/intel\%C2\%AEeducation-no-brasil> Acesso em 10 de Março de 2015.

Ferreira, V. H., Wagner, P. R. (2012) A Tecnologia na Escola: Analisando o Perfil Tecnológico do Aluno de Ensino Médio. Anais do XXIII Simpósio Brasileiro de Informática na Educação. Rio de Janeiro. Brasil.

Myron, J. A.; Black, P. Changing the Subject: Innovations in Science, Maths and Technology Education. New York: Routledge, 1996. 240p.

Scaico, P. D., Queiroz, R. J. G. B. (2013) A educação do futuro: uma reflexão sobre aprendizagem na era digital. Anais do XXIV Simpósio Brasileiro de Informática na Educação. Campinas. Brasil.

Secretaria de Educação e Esportes de Pernambuco. Balanço da Educação 2014. Disponível em: http://www.educacao.pe.gov.br/portal/upload/galeria/8015/BalancoDaEducacao_201 4_site.pdf> Acesso em 11 de Março de 2015. 